\section{Significados, percepção de risco e estratégias de prevenção de gestantes após o surgimento do Zika vírus no Brasil}

\author{
Meanings, risk perceptions, and prevention \\ strategies for pregnant women since the \\ emergence of the Zika virus in Brazil
}

\author{
Significados, percepción de riesgo y estrategias \\ de prevención de gestantes tras el surgimiento \\ del virus Zika en Brasil
}

Fernanda Macedo da Silva Lima ${ }^{1}$

Jorge Alberto Bernstein Iriart 1

\section{Resumo}

Este estudo teve como objetivo compreender significados, percepção de risco e estratégias de prevenção da infecção pelo Zika vírus desenvolvidas por gestantes com diferentes condições socioeconômicas, atendidas em serviços de saúde público e privado da cidade de Salvador, Bahia, Brasil, bem como a contribuição de seus parceiros para lidar com o risco de infecção após o surgimento desse vírus no país. Foi realizado um estudo qualitativo, a partir do desenvolvimento de 18 entrevistas semiestruturadas, sendo nove com gestantes atendidas pelo setor público de saúde e nove com gestantes atendidas pelo setor privado de saúde. Os dados produzidos demonstraram insuficiências no conhecimento das gestantes sobre aspectos importantes da infecção pelo Zika vírus. A situação socioambiental na qual as gestantes estão submetidas foi um fator importante para a percepção de risco e estratégias de prevenção. Gestantes entrevistadas no setor público de saúde demonstraram se sentir mais vulneráveis ao risco de infecção no ambiente em que vivem do que gestantes entrevistadas no setor privado de saúde, com grande impacto sobre o seu bem-estar psicossocial. Segundo as gestantes, os parceiros exerceram intensa cobrança para que elas adotassem ações preventivas sem, no entanto, realizarem os mesmos cuidados, desconsiderando o risco de transmissão do vírus por via sexual. Conclui-se que, após aproximadamente três anos da epidemia no país, o Zika vírus ainda possui um grande impacto sobre a vida das gestantes é imprescindivel fortalecer as ações de comunicação em saúde para assegurar a disponibilização de informações que respondam adequadamente às necessidades da população sobre a doença.

Zika Virus; Gravidez; Microcefalia; Gestão de Riscos; Gênero e Saúde

\author{
Correspondência \\ F. M. S. Lima \\ Instituto de Saúde Coletiva, Universidade Federal da Bahia. \\ Rua Basílio da Gama s/n, Campus Universitário, Salvador, BA \\ 40110-040, Brasil. \\ nanda_msl@hotmail.com \\ 1 Instituto de Saúde Coletiva, Universidade Federal da Bahia, \\ Salvador, Brasil.
}




\section{Introdução}

Em 2015, foi identificado o primeiro caso de infecção autóctone pelo Zika vírus (ZIKV) no Brasil. O ZIKV é transmitido principalmente pela picada do mosquito Aedes aegypti, endêmico no país há mais de três décadas ${ }^{1}$. Além dessa via de infecção, o ZIKV pode ser transmitido por via transplacentária, o que atraiu grande atenção global em decorrência das consequências da infecção durante a gestação 2,3.

A microcefalia em recém-nascidos foi a primeira alteração associada à infecção intrauterina pelo ZIKV. Posteriormente, outras malformações congênitas também foram identificadas, condição atualmente conhecida como síndrome congênita do Zika vírus (SCZ) 4,5. Entre 2015 e 2016, foram notificados quase 10 mil casos suspeitos da SCZ no Brasil, desses, 2.018 foram confirmados. Esses casos se concentraram principalmente na Região Nordeste do país, sendo que a Bahia foi o segundo estado nordestino com o maior número de casos notificados 6. O Município de Salvador registrou altos índices da SCZ, com 105 casos confirmados em 2015 e 130 casos confirmados em 2016 7. O aumento do número de nascimentos de crianças com a SCZ fez com que o Ministério da Saúde e, posteriormente, a Organização Mundial da Saúde (OMS) declarassem a epidemia do ZIKV como uma emergência de saúde pública 2,8.

A partir de 2016, observou-se importante declínio no número de casos de infecções pelo ZIKV e da SCZ no país. Essa redução é sugestiva do desenvolvimento de imunidade por grupos que não possuíam histórico de exposição anterior ao vírus 9,10. Apesar dessa redução, o ZIKV permanece como um risco à saúde, visto que, mesmo em países altamente acometidos como o Brasil, ainda persistem grupos populacionais que não foram expostos ao vírus e, consequentemente, não possuem imunidade desenvolvida. Adicionalmente, uma série de questões sobre o ZIKV ainda não foram completamente elucidadas, não podendo afastar o risco de novos surtos. Sendo assim, é fundamental manter a vigilância constante e investir na produção de conhecimento científico para uma melhor compreensão sobre a infecção pelo ZIKV e seus impactos 10,11.

Doenças transmitidas por mosquitos não são definidas como enfermidades exclusivas da pobreza, já que elas atingem regiões ricas e pobres da cidade. Entretanto, as consequências da infecção pelo ZIKV apresentaram repercussões muito diferentes em termos de classe, raça/etnia e gênero, caracterizando-se como um marcador contemporâneo de desigualdade no país ao aumentar a vulnerabilidade de grupos sociais já expostos a precárias condições de vida 12. Segundo dados do Ministério da Saúde, os grupos mais atingidos pela epidemia foram mulheres em idade reprodutiva, pessoas que se autodeclararam pardas e com menores índices de escolaridade 13.

Essa conjuntura apresentou grande impacto sobre a vida das mulheres em idade reprodutiva e gestantes no país. De acordo com o estudo desenvolvido por Meireles et al. 14 em Juiz de Fora (Minas Gerais), com 14 mulheres grávidas, o período gestacional se tornou um momento de intenso sofrimento psicológico marcado por sentimentos de preocupação, ansiedade e/ou medo frente ao risco de infecção pelo ZIKV. Esse contexto também fez com que essas mulheres desenvolvessem novos hábitos de proteção, como evitar locais de risco e o uso constante de repelentes. O trabalho realizado por Linde \& Siqueira 15 com 18 mulheres em idade reprodutiva no Brasil, Porto Rico e Estados Unidos para avaliar o impacto social da epidemia em diferentes localidades também identificou que as mulheres passaram a desenvolver medidas de proteção que repercutiram em suas rotinas familiares e profissionais, com impactos sobre o bem-estar psicossocial.

Apesar dos avanços da literatura sobre o tema, ainda não existem investigações sobre significados, percepção de risco e estratégias de prevenção desenvolvidas por gestantes de distintos estratos sociais. A compreensão dos significados, percepções e práticas com relação ao risco de contrair o ZIKV deve ser orientada por modelos teóricos que reconheçam que o comportamento humano é socialmente construído, e que a tomada de decisão dessas mulheres é influenciada por normas e valores culturais presentes no contexto social no qual elas se encontram inseridas, assim como por limitações de ordem socioeconômicas.

A percepção de risco, portanto, não está relacionada apenas à consequência direta dos perigos em sua dimensão biológica. De acordo com Douglas \& Wildavsky 16 e Lupton 17, ela é uma construção coletiva que sofre influências de crenças e valores compartilhados dentro de contextos socioculturais específicos e pode apresentar compreensões distintas entre os diversos grupos sociais. Diante disso, o 
risco é uma construção social sobre um perigo que existe em sua dimensão objetiva, porém o entendimento desse fenômeno só pode ser alcançado mediante processos socioculturais.

Com base nessas premissas, este estudo teve como objetivo compreender significados, percepção de risco e estratégias de prevenção da infecção pelo ZIKV desenvolvidas por gestantes com diferentes condições socioeconômicas, atendidas em serviços de saúde público e privado da cidade de Salvador, bem como a contribuição de seus parceiros para lidar com o risco de infecção após o surgimento desse vírus no Brasil.

\section{Metodologia}

Trata-se de um estudo de abordagem qualitativa e de cunho socioantropológico. A produção de dados ocorreu entre agosto e outubro de 2018 em uma unidade de saúde da família (USF) e em uma clínica privada para assistência obstétrica em Salvador. Foram realizadas 18 entrevistas semiestruturadas, sendo nove com gestantes atendidas pelo Sistema Único de Saúde (SUS) e nove com gestantes atendidas pelo setor privado de saúde.

$\mathrm{O}$ recrutamento das gestantes visou assegurar heterogeneidade socioeconômica, cultural e ambiental entre as participantes do estudo que foram selecionadas da seguinte maneira: (1) gestantes que acessam os serviços públicos de saúde e residem em bairros populares; (2) gestantes que acessam os serviços privados de saúde e residem em bairros de classe média/alta. Ressalta-se que a clínica privada escolhida para este estudo só aceitava pagamento por desembolso direto, o que selecionava pacientes de alta renda. Sendo assim, a escolha de uma USF que atende uma população predominantemente das camadas populares e uma clínica privada que atende uma população de classe média/alta visou, sobretudo, contrastar a experiência da gestação nesses diferentes universos em um contexto pós-epidemia do ZIKV.

Além disso, foram incluídas mulheres em diferentes períodos gestacionais, pois o ZIKV pode apresentar repercussões diferentes a depender do momento que a gestante for acometida, o que pode influenciar na percepção de risco dessas mulheres. Por fim, algumas heterogeneidades surgiram naturalmente como diferenças de faixas etárias, raça/etnia, nível de escolaridade, situação conjugal e vínculos empregatícios.

Na USF, as gestantes foram convidadas a participar da pesquisa no momento que aguardavam a consulta de pré-natal ou durante as visitas domiciliares realizadas com os agentes comunitários de saúde. As entrevistas ocorreram na própria USF ou na residência das gestantes. Na clínica privada, as gestantes também foram recrutadas enquanto aguardavam a consulta de pré-natal, e as entrevistas aconteceram na própria clínica, na residência das gestantes ou em seu ambiente de trabalho.

$\mathrm{O}$ roteiro das entrevistas abordou as seguintes temáticas: conhecimento sobre o ZIKV e significado atribuído, percepção de risco e estratégias de cuidado adotadas pelas gestantes, mudanças de comportamento após o surgimento do ZIKV no Brasil, orientações dos serviços de saúde sobre o ZIKV e relações de gênero. As entrevistas foram gravadas em dispositivo de áudio com duração média de 40 minutos.

A análise dos dados foi desenvolvida a partir da técnica de análise de conteúdo temática 18 . Neste estudo, partiu-se do pressuposto que os significados e práticas associados a saúde, doença e risco são concebidos dentro de contextos socioculturais específicos 19. Nesta pesquisa, foi utilizado o software de análise qualitativa NVivo, versão 8 (https://www.qsrinternational.com/nvivo/home), que auxiliou na codificação dos dados para posterior análise e interpretação.

A pesquisa foi aprovada pelo Comitê de Ética em Pesquisa do Instituto de Saúde Coletiva da Universidade Federal da Bahia (CEP-ISC/UFBA), sob parecer no 2.770.514. O trabalho cumpriu as recomendações da Resolução no 466/2012 da Comissão Nacional de Ética em Pesquisa. Nomes fictícios foram atribuídos às entrevistadas a fim de preservar-lhes o anonimato. 


\section{Caracterização das participantes do estudo}

A idade das gestantes variou entre 19 e 41 anos. Entre as gestantes entrevistadas no setor privado de saúde, quatro se autodeclararam brancas, quatro pardas, e uma não soube responder. Entre as gestantes entrevistadas no SUS, seis se autodeclararam pretas, duas pardas e uma branca. Quanto à situação conjugal, oito mulheres entrevistadas no setor privado de saúde estavam casadas e uma solteira; para oito dessas gestantes, essa era a primeira gestação, enquanto apenas uma possuía um filho. Entre as mulheres entrevistadas no SUS, seis declararam morar junto, duas casadas e uma solteira, enquanto, para apenas três dessas mulheres, essa era a primeira gestação. Todas as gestantes entrevistadas no setor privado de saúde possuíam vínculos empregatícios formais e ensino superior completo, com exceção de uma gestante que estava afastada do seu trabalho no momento da entrevista e possuía ensino superior incompleto. Entre as gestantes entrevistadas no SUS, apenas duas possuíam vínculos formais de trabalho e ensino superior completo, enquanto as demais eram autônomas ou estavam desempregadas, e o nível de escolaridade variou entre ensino médio incompleto e completo (Quadros 1 e 2).

\section{Resultados e discussão}

\section{Conhecimento sobre o ZIKV e significado atribuído por gestantes}

Existem importantes variações na compreensão sobre o ZIKV entre as mulheres deste estudo. Gestantes entrevistadas no setor privado de saúde relataram possuir poucas informações sobre o ZIKV, restritas principalmente às formas de transmissão, aos sinais e sintomas da doença e aos riscos associados à infecção durante a gestação:

\section{Quadro 1}

Perfil das mulheres atendidas pelo setor privado de saúde, segundo características sociodemográficas e reprodutivas. Salvador, Bahia, Brasil.

\begin{tabular}{|c|c|c|c|c|c|c|c|}
\hline Nome & Raça/Cor & $\begin{array}{l}\text { Idade } \\
\text { (anos) }\end{array}$ & $\begin{array}{l}\text { Trimestre } \\
\text { gestacional }\end{array}$ & Filhos & $\begin{array}{c}\text { Estado civil/ } \\
\text { Situação conjugal }\end{array}$ & Ocupação & Escolaridade \\
\hline Ester & Branca & 30 & 3o & 0 & Casada & $\begin{array}{c}\text { Fisioterapeuta/Professora/ } \\
\text { Coordenadora de instituição de } \\
\text { Ensino Superior }\end{array}$ & $\begin{array}{l}\text { Ensino Superior } \\
\text { completo }\end{array}$ \\
\hline Francisca & Parda & 33 & 3o & 0 & Casada & Dentista & $\begin{array}{c}\text { Ensino Superior } \\
\text { completo }\end{array}$ \\
\hline Maria & Branca & 29 & 3o & 0 & Casada & Médica veterinária & $\begin{array}{l}\text { Ensino Superior } \\
\text { completo }\end{array}$ \\
\hline Jaqueline & Branca & 30 & 3o & 1 & Casada & Engenheira mecânica & $\begin{array}{c}\text { Ensino Superior } \\
\text { completo }\end{array}$ \\
\hline Milena & Não sabe & 25 & $2 \underline{0}$ & 0 & Solteira & Modelo & $\begin{array}{c}\text { Ensino Superior } \\
\text { incompleto }\end{array}$ \\
\hline Laura & Parda & 28 & $2 ㅇ$ & 0 & Casada & Nutricionista & $\begin{array}{l}\text { Ensino Superior } \\
\text { completo }\end{array}$ \\
\hline Alcione & Parda & 28 & $2 \underline{0}$ & 0 & Casada & Dentista & $\begin{array}{c}\text { Ensino Superior } \\
\text { completo }\end{array}$ \\
\hline Andréa & Parda & 36 & $2 \underline{0}$ & 0 & Casada & Psicóloga & $\begin{array}{c}\text { Ensino Superior } \\
\text { completo }\end{array}$ \\
\hline Adelaide & Branca & 30 & $1 \underline{0}$ & 0 & Casada & $\begin{array}{c}\text { Administradora/Contadora/ } \\
\text { Empresária }\end{array}$ & $\begin{array}{c}\text { Ensino Superior } \\
\text { completo }\end{array}$ \\
\hline
\end{tabular}


Quadro 2

Perfil das mulheres atendidas pelo Sistema Único de Saúde (SUS), segundo características sociodemográficas e reprodutivas. Salvador, Bahia, Brasil.

\begin{tabular}{|c|c|c|c|c|c|c|c|}
\hline Nome & Raça/Cor & Idade (anos) & $\begin{array}{l}\text { Trimestre } \\
\text { gestacional }\end{array}$ & Filhos & $\begin{array}{c}\text { Estado civil/Situação } \\
\text { conjugal }\end{array}$ & Ocupação & Escolaridade \\
\hline Aurora & Preta & 30 & 3으 & 1 & Mora junto & $\begin{array}{c}\text { Auxiliar de serviços } \\
\text { gerais }\end{array}$ & $\begin{array}{l}\text { Ensino Médio } \\
\text { incompleto }\end{array}$ \\
\hline Nadja & Preta & 39 & 3으 & 3 & Casada & Dona de casa & $\begin{array}{l}\text { Ensino Médio } \\
\text { completo }\end{array}$ \\
\hline Tania & Preta & 19 & 3o & 0 & Solteira & Desempregada & $\begin{array}{c}\text { Ensino Médio } \\
\text { incompleto }\end{array}$ \\
\hline Teresa & Branca & 29 & 30 & 1 & Mora junto & Autônoma & $\begin{array}{l}\text { Ensino Médio } \\
\text { completo }\end{array}$ \\
\hline Rita & Preta & 39 & 20 & 0 & Mora junto & Jornalista & $\begin{array}{c}\text { Ensino Superior } \\
\text { completo }\end{array}$ \\
\hline Júlia & Parda & 30 & 20 & 1 & Mora junto & Desempregada & $\begin{array}{l}\text { Ensino Médio } \\
\text { incompleto }\end{array}$ \\
\hline Antônia & Preta & 41 & 20 & 0 & Mora junto & Dentista & $\begin{array}{c}\text { Ensino Superior } \\
\text { completo }\end{array}$ \\
\hline Isadora & Preta & 23 & 20 & 1 & Casada & Desempregada & $\begin{array}{l}\text { Ensino Médio } \\
\text { completo }\end{array}$ \\
\hline Angélica & Parda & 24 & 10 & 1 & Mora junto & $\begin{array}{l}\text { Vendedora de } \\
\text { cosméticos }\end{array}$ & $\begin{array}{c}\text { Ensino Médio } \\
\text { completo }\end{array}$ \\
\hline
\end{tabular}

"O que eu conheço? É que é um vírus que há três ou quatro anos atrás foi descoberto na verdade em humanos, acho que era circulado só entre animais, não vou lembrar qual... E que é transmitido pelo mesmo mosquito que transmite a dengue e que, em contato com mulheres grávidas, aparentemente causa alterações na morfologia do cérebro, né? Do crânio do bebê. É isso, basicamente isso. Têm pessoas que são picadas e que o bebê desenvolve microcefalia e têm pessoas que são picadas e que não desenvolve, o bebê não desenvolve, talvez tenha a ver com o tipo, com uma mutação, até onde eu sei é isso aí... E, que mais? Os sintomas são muitos parecidos com os da dengue, mas se eu não me engano é um pouco mais brando..." (Ester, 30 anos, setor privado).

Enquanto, entre gestantes entrevistadas no SUS, o conhecimento sobre a doença dizia respeito principalmente à experiência de mães de crianças com microcefalia evidenciadas pela mídia e o medo associado a essa infecção durante a gestação:

"Eu conheço, tipo, pela televisão, que eu vejo aquelas mães passando com aquele bebê (...) tipo, que o mosquito infectado te picando, seu bebê pode vim com essa doença, com problemas, é isso que eu acho que todo mundo ouve, que vê passando na televisão, que vê aquela luta daquelas mães com os bebês subindo e descendo, mas, na verdade eu nem entendo muito sabe, de Zika vírus...” (Júlia, 30 anos, SUS).

Após aproximadamente três anos do início da epidemia do ZIKV no país, é possível perceber que ainda persistem muitas dúvidas e poucas informações sobre a doença. Resultados semelhantes também foram encontrados em outros estudos nacionais 20,21 e internacionais 22 ao constatarem que existe uma fragilidade na compreensão sobre a doença entre mulheres em idade reprodutiva, limitando-se à forma de transmissão do vírus, em especial pela picada dos mosquitos, e ao risco do desenvolvimento da microcefalia em recém-nascidos. Apesar de todas as mulheres deste estudo estarem vinculadas aos serviços de saúde para o acompanhamento pré-natal, isso pareceu não repercutir no nível de conhecimento sobre a doença, o que sugere insuficiências nas orientações fornecidas por profissionais de saúde sobre o ZIKV e suas consequências. Segundo as mulheres entrevistadas, a orientação dos profissionais limitou-se à recomendação do uso do repelente: 
"Não, não. Só mesmo passar o repelente pra mosquitos de uma maneira geral, só" (Alcione, 28 anos, setor privado).

"Pra falar a verdade? Não. Assim, a única coisa que eu ouvi foi que eu tinha que usar o repelente pra prevenir. Mas... só isso. Eu não ouvi nada além disso...” (Júlia, 30 anos, SUS).

Em relação à percepção do ZIKV como um problema de saúde, essa é bem difundida entre todas as gestantes. Apesar de muitas mulheres deste estudo mencionarem que o país não vive mais uma epidemia, há a compreensão de que a gestação é um período vulnerável, tendo em vista as consequências que uma infecção durante esse momento pode acarretar, o que demanda maiores cuidados. Todavia, para essas mulheres, fora da gestação, a infecção não oferece grandes preocupações:

“...O problema do Zika é porque, é justamente em relação à grávida, não é? Porque as consequências são muito mais graves, pelo menos isso é o que é passado pela mídia, porque eu não estudei sobre isso, então o que foi passado pela mídia é que as consequências do Zika são as piores de todos, de todas essas doenças da atualidade, é, o fato da grávida, da mulher ter um bebê que não vai se desenvolver, né? (...) A única questão que me dá medo em relação ao Zika é por causa do bebê, a questão da microcefalia e tal, mas assim, se eu não tivesse grávida, eu não teria medo de pegar Zika..." (Francisca, 33 anos, setor privado).

Os veículos de comunicação em massa desempenharam um papel fundamental em divulgar a epidemia do ZIKV e suas consequências sobre o desenvolvimento infantil. Sendo assim, jornais, televisão e Internet exerceram grande influência sobre a maneira como a população compreendeu esse novo problema de saúde 3,23 , com significativas repercussões sobre mulheres grávidas ou que planejavam engravidar após esse período. Estudos realizados com mulheres em idade reprodutiva e gestantes demonstraram que a epidemia do ZIKV teve grande impacto sobre o seu bem-estar psicossocial, ocasionando sentimentos constantes de medo, angústias e incertezas 14,15.

Nosso estudo corrobora com esses achados, mas sugere que os significados atribuídos ao vírus podem variar entre mulheres de diferentes estratos sociais, visto que elas também possuem distintos graus de exposição ao risco de infecção. Embora todas as mulheres deste estudo reconheçam que uma infecção pelo ZIKV possui graves consequências, com influência sobre o seu bem-estar psicossocial, gestantes entrevistadas no setor privado de saúde retratam o ZIKV como uma "apreensão" ou "uma preocupação a mais durante a gravidez". Algumas até consideram o ZIKV como "um problema que foi sanado", dada a redução do número de crianças nascendo com alterações. Em contrapartida, gestantes entrevistadas no SUS construíram significados sobre o ZIKV como uma "doença muito grave" e que desenvolve sentimentos de "medo" e "pânico", fazendo com que elas passem a "gravidez inteira insegura"

A percepção de maior gravidade associada à epidemia do ZIKV e suas consequências pelas mulheres das camadas populares atendidas no SUS está associada a sua percepção de maior vulnerabilidade à infecção pelo mosquito por conta das condições socioeconômicas e sobretudo ambientais que elas enfrentam nos bairros populares, ponto que será aprofundado na próxima seção.

\section{Percepção de risco ambiental e estratégias de cuidado desenvolvidas por gestantes após o surgimento do ZIKV no Brasil}

A epidemia do ZIKV no Brasil acometeu milhares de pessoas. No entanto, suas consequências foram mais acentuadas entre indivíduos de menores condições socioeconômicas 12,24. Neste estudo, gestantes entrevistadas no SUS relataram intensa preocupação com o ambiente em que vivem. Apesar de desenvolverem ações de cuidado em suas residências, essas são insuficientes, visto que o bairro em que residem oferece riscos constantes que fogem do controle individual:

"Um risco, eu fico pensando no risco que pode causar... que pode causar não, né? Que ele causa. (...) Principalmente assim, a gente que mora em bairro pequeno, bairro que tem essas dificuldades, né? Sempre tem esses negócios aí como eu falei, esse risco aí dessa senhora [a senhora que mora na frente da casa dela trabalha com reciclagem e acumula objetos que contribuem para a proliferação do vetor], aí que eu fico mesmo pensando, eu nem saio aí, apesar que pra ser mordida não... Mas eu evito o máximo de ficar aí fora. (...) Os vizinhos aqui não ajudam, água empoçada, e assim, a sujeira dela tudo ela bota ali. Então, tudo isso fica exposto, né? Lixo, rato... Aí eu tenho medo. (...) Não adianta aqui fazer e na rua... Porque, quando é uma coisa que é distante de você, agora uma coisa perto, é complicado..." (Isadora, 23 anos, SUS).

Por outro lado, gestantes entrevistadas no setor privado de saúde relataram se sentir protegidas no ambiente que residem. Essas mulheres afirmam que esporadicamente visitam locais com maior 
circulação de mosquitos e, por isso, possuem algum grau de exposição ao risco de infecção. Porém, esses ambientes não fazem parte da sua rotina e podem ser facilmente evitados durante a gestação:

"Não, diariamente não. Final de semana sim, a casa dos meus pais sim. Eles moram em casa, lá eu sei que tem mosquitos e eu já sei que é um mosquitinho rajadinho, então eu me sinto mais exposta aos finais de semana quando eu vou pra lá, mas no meu dia a dia, durante a minha semana, é raro, pouquíssimo, porque aqui não tem, é muito alto e no trabalho também eu nunca percebi" (Ester, 30 anos, setor privado).

A maioria das gestantes entrevistadas no setor privado de saúde deste estudo relataram viver em altos edifícios onde o acesso do mosquito é menor, o que resulta em uma baixa percepção de risco ambiental entre essas mulheres.

Dessa maneira, a epidemia do ZIKV evidenciou a influência da estratificação social e do contexto ambiental na situação de saúde da população. Esse vírus afetou principalmente mulheres que dispõem de menor condição socioeconômica e possuem piores condições de moradia, abastecimento hídrico e saneamento básico, o que resulta em altos índices de exposição ao risco e infecção 12,24,25. Em contrapartida, o estudo realizado por Marteleto et al. 26 sugere que mulheres com melhores condições socioeconômicas tendem a se sentir mais protegidas por residir em altos edifícios ou em melhores regiões da cidade, além de poderem contar com adequadas condições de infraestrutura, achados consonantes com nosso estudo.

A esse respeito, o conceito de vulnerabilidade socioambiental de Spink 27 é importante para compreender como os riscos sociais e ambientais resultam em impactos especialmente sobre grupos populacionais mais pobres. Esses residem em locais com piores condições de vida e estão mais susceptíveis às consequências das alterações ambientais. Nesse sentido, o estudo de Nawrotzki et al. 28 realizado em uma região metropolitana do Brasil, reforça que a precariedade das condições ambientais locais está associada a um aumento da preocupação ambiental em grupos com menores níveis socioeconômicos. Assim, os contextos social, cultural e ambiental influenciam a maneira como os indivíduos percebem as situações de risco relacionadas à saúde, bem como os métodos de prevenção utilizados para lidar com eles 19 .

As gestantes deste estudo desenvolveram novos hábitos diários para reduzir o risco de infecção pelo ZIKV. Dentre as ações, estão a supervisão do domicílio, cuidados corporais para evitar a picada dos mosquitos e restrição de visitas às áreas de risco, condutas fortemente recomendadas durante a epidemia. As ações ambientais de controle dos mosquitos foram mais evidentes entre gestantes entrevistadas no SUS que relataram dedetizar o ambiente e supervisionar os possíveis criadouros de mosquitos. Essas práticas foram menos constantes entre gestantes entrevistadas no setor privado de saúde por demonstrarem se sentir mais seguras no ambiente em que vivem.

O uso do repelente para proteção corporal foi uma prática muito adotada entre gestantes, orientada por profissionais da saúde e recomendada por instituições oficiais 2,14,29. Neste estudo, o repelente passou a fazer parte da rotina diária de muitas mulheres:

“...E eu uso agora o repelente todos os dias, acordou, tomou banho, não é mais hidratante, é repelente. $O$ cheiro é horrivel, eu fico enjoada, todo mundo fala que o cheiro é bom, mas eu não gosto, fico enjoada, mas eu uso. É meu hidratante" (Rita, 39 anos, SUS).

"E inclui muito também por pressão do meu marido, o uso do repelente, né? (...) Então assim, tem repelente aqui, tem repelente no carro dele, tem repelente no meu carro, em todos os lugares tem repelente..." (Andréa, 36 anos, setor privado).

No entanto, o uso do repelente não foi uma prática unânime, e algumas mulheres relataram dificuldades em usar o produto pelo seu forte cheiro ou por acharem não ser uma prática totalmente eficiente. Houve ainda relatos de que o uso do repelente seria fundamental apenas nos momentos iniciais da gestação e que poderia ser dispensado à medida que a gravidez avança, o que contraria a literatura científica que afirma que a infecção pelo ZIKV, em qualquer período gestacional, pode causar repercussões sobre o desenvolvimento fetal 5 .

A necessidade do uso do repelente foi mais evidente entre gestantes entrevistadas no SUS, provavelmente por se sentirem mais expostas ao vetor no ambiente em que vivem. Porém, o acesso a esse produto nem sempre era facilitado. Gestantes que realizam o pré-natal no SUS têm direito de retirar o repelente nas USF sem nenhum custo 30 . Entretanto, em alguns momentos, esse produto esteve indisponível, e as gestantes relataram a necessidade de realizar esforços adicionais para adquiri-lo ou contar com o auxílio financeiro de amigas e até mesmo utilizar outros cremes corporais na tentativa 
de evitar as picadas, pois não possuíam condições financeiras para comprar. Em contrapartida, gestantes entrevistadas no setor privado de saúde que utilizavam o repelente diariamente não relatavam dificuldades para adquiri-lo e afirmavam possuir mais de uma unidade do produto.

Por fim, algumas gestantes também mencionaram que se privam de visitar locais com maior circulação de mosquitos a fim de evitar a exposição ao risco de infecção:

"Ah, sim. Demais. Porque imagine, você tá, assim ó, pelo menos o que eu penso, você tá grávida, você quer curtir a gravidez... Não que você não tenha que se prevenir, não que você tenha o cuidado, mas tipo, você quer curtir mais o seu bebê, você quer ir num parque, você quer ir despreocupada, aí de repente você ouve tanta coisa e você fica com medo, eu no meu caso mesmo, eu ir no parque da cidade? Nem no sonho, porque tem muito mato, muita coisa, então tipo, você fica com medo, você fica, sabe, apreensiva. (...) É como eu falei, eu acho que até eu ter o bebê, eu vou ficar nesse pânico, sabia? Até eu saber assim, que meu filho nasceu saudável, perfeito, meu Deus... Parque da cidade, nem no sonho!..." (Júlia, 30 anos, SUS).

Dessa maneira, todas essas modificações nos hábitos e rotinas das gestantes têm produzido impactos sobre seu bem-estar psicossocial. Nesse contexto, essas mulheres passaram a ter que administrar a felicidade de estar grávida com a insegurança e a responsabilidade de gestar após o surgimento do ZIKV no país, tendo em vista os riscos que esse novo cenário proporciona.

\section{Contribuição dos parceiros para lidar com o risco de infecção pelo ZIKV}

As gestantes deste estudo relataram a participação ativa dos parceiros nos cuidados ambientais para eliminar possíveis focos de proliferação do vetor. No entanto, os cuidados corporais para evitar a picada dos mosquitos não eram um comportamento habitual entre os homens. A participação dos parceiros se restringia em lembrar ou cobrar as mulheres quanto ao uso do repelente:

"Ele é super atento com esse negócio de vasilha, lugar com água e tal, ele só não usa o repelente, mas com o ambiente ele é preocupado..." (Rita, 39 anos, SUS).

"Ele é bem participativo, é, ele é preocupado, ele me lembra do repelente, me lembra da roupa comprida, ele é atento a isso, se a gente tá em um lugar e ele sente mosquitos, ele já me pergunta 'trouxe o repelente?' (...) Meu marido foi pra o treinamento, nesse processo seletivo que ele passou, que era no mato, eu falei pra ele várias vezes 'olha, leva o repelente, tu não pode pegar, leva o repelente, leva o repelente..., mas ele sabe, mas ele tem mais cuidado comigo do que com ele, entendeu? Apesar dele saber, mas ele pensa mais em mim, 'passa repelente, cuidado com o mosquito,', do que nele..." (Francisca, 33 anos, setor privado).

Resultados semelhantes foram encontrados por Meireles et al. 14 ao demonstrar que os parceiros exercem intensa cobrança quanto ao uso de repelentes pelas gestantes, mas não há registros neste estudo de cuidados por parte dos homens para evitar uma infecção. O estímulo para a adoção de cuidados corporais foi direcionado principalmente às mulheres e fortemente incentivado durante a epidemia, mas essas recomendações pouco destacavam a importância da participação dos parceiros, apesar da possibilidade de transmissão sexual do ZIKV 12,31.

A esse respeito, o conhecimento sobre a transmissão sexual do vírus era bem difundido entre gestantes entrevistadas no setor privado de saúde, entretanto essa informação causou surpresa em muitas das gestantes entrevistadas no SUS. Nesse sentido, ao serem questionadas sobre a disponibilidade de o parceiro utilizar o preservativo durante a gravidez frente aos riscos da transmissão sexual do vírus, algumas mulheres mencionaram essa possibilidade apenas em casos de sinais e sintomas ou diagnóstico de infecção:

"Eu acho que sim, para proteger o bebê, eu acho que a gente faria qualquer coisa. Não só ele como eu também. (...) Ele não gosta de usar o preservativo não, vou ser bem sincera com você, mas, no caso, para proteger o nosso filho, eu acho que sim. Acho, tenho certeza que sim. (...) Acho que só se ele fizesse o exame ou tivesse algum sintoma, detectasse alguma coisa" (Aurora, 30 anos, SUS).

"Se ele tivesse infectado, sim. Com certeza. Com certeza. Ou outros métodos até suspensão, com certeza, se precisasse para a nossa segurança e da bebê, com certeza. (...) Em uma prevenção, eu já acho que... Não sei, não tenho certeza. No caso diagnosticado, certamente" (Jaqueline, 30 anos, setor privado).

A utilização do preservativo apenas em casos de sintomas evidentes ou diagnóstico clínico se caracteriza como um comportamento equivocado, pois grande parte dos casos de infecção pelo ZIKV são assintomáticos, sendo recomendado o uso de métodos contraceptivos de barreira durante toda a gestação 2,29,32. No entanto, a adoção desse comportamento para mitigar o risco não é uma prática comum 
entre os homens. O estudo desenvolvido por Marteleto et al. 26 evidenciou acentuada resistência por parte dos parceiros quanto ao uso do preservativo e reduzido poder de negociação das mulheres sobre práticas sexuais mais seguras, em especial entre as de menores estratos socioeconômicos.

A forma como se estruturam as relações de gênero determina a situação de vulnerabilidade imposta a essas mulheres. Essas relações são permeadas por assimetrias de poder e disparidades em esferas sociais, econômicas e culturais que influenciam a experiência feminina e dificultam a possibilidade de negociação do preservativo com seus parceiros 33 . Na tentativa de reduzir essas desigualdades, uma gestante desse estudo sugeriu o investimento em ações de prevenção que estimulem a autonomia feminina. Para ela, a submissão das mulheres a relações sexuais desprotegidas e de risco é uma consequência da dificuldade de acesso a métodos que garantam sua liberdade de escolha:

"Até porque eu acho que hoje em dia os homens têm mais acesso à camisinha masculina do que as mulheres. Que eu não vejo, se você vai no posto, eu vejo mais entregando camisinha masculina, feminina muito difícil, eu nunca vi. É tanto que eu nem conhecia, eu vim conhecer deve ter uns três ou quatro anos, foi em um trabalho no colégio e aí uma colega da gente conseguiu no posto, que eu acho que a tia dela trabalhava lá e aí conseguiu uma camisinha feminina e ai a gente veio conhecer como é que se usava e tudo mais. Fora isso, eu acho que deveria ter...as mulheres deveriam ter mais acesso à camisinha feminina porque a maioria das mulheres querem usar, e o homem não quer usar..." (Tania, 19 anos, SUS).

Estudos demonstram, no entanto, que a simples disponibilização de métodos contraceptivos femininos não garante sua ampla utilização, tendo em vista as assimetrias de poder existentes entre os gêneros 34. Assim, para que haja um maior engajamento masculino nas ações de prevenção, é necessário tornar os parceiros corresponsáveis pela gestação e segurança do desenvolvimento fetal. A inclusão dos homens no acompanhamento pré-natal é uma importante estratégia para estimular a paternidade ativa e consciente, pois esse espaço permite disponibilizar orientações e métodos que diminuam os riscos de infecção e reforçar a importância do envolvimento do parceiro em toda a gravidez, parto, puerpério e cuidados com a criança 2.

Nesse sentido, torna-se imprescindível o investimento em políticas públicas que ampliem a disponibilização de informações e insumos para a prevenção da infecção em gestantes. Além disso, o Estado deve assegurar o exercício dos diretos reprodutivos a todas as mulheres, preservando sua autonomia e direito de escolha em casos de suspeita ou confirmação da infecção intrauterina pelo ZIKV, seguida do desejo, ou não, de interrupção da gravidez. Essa decisão está relacionada com o bem-estar psicossocial dessas mulheres. No entanto, caso desejem prosseguir com a gravidez, cabe ao Estado prestar total assistência à mãe e à criança 1,35 .

\section{Considerações finais}

O presente estudo sugere a existência de variações nos conhecimentos, percepção de risco e estratégias de prevenção desenvolvidas por gestantes após o surgimento do ZIKV no país. Aproximadamente três anos depois da epidemia, é possível perceber que persistem insuficiências na orientação fornecida às mulheres durante o pré-natal e no conhecimento dessas mulheres sobre aspectos importantes da infecção pelo ZIKV. Dada a incerteza sobre novos surtos de ZIKV em cenários futuros ${ }^{9}$, seria importante que os serviços estivessem preparados para disponibilizar informações que respondam adequadamente às necessidades da população sobre a doença. Para isso, é necessário fortalecer as ações de comunicação em saúde e desenvolver programas para a qualificação dos profissionais de saúde.

A situação socioambiental na qual as gestantes estão submetidas foi um fator importante para a percepção de risco e estratégias de prevenção. Gestantes entrevistadas no SUS demonstraram se sentir mais vulneráveis ao risco de infecção no ambiente em que vivem do que gestantes entrevistadas no setor privado de saúde. De maneira geral, esse contexto demandou dessas mulheres novos hábitos de vida na tentativa de evitar a infecção pelo ZIKV. Apesar de importantes na prevenção da infecção, as ações dos parceiros se restringiam ao ambiente, desconsiderando os cuidados corporais. Assim, é imprescindível investir em ações de saúde que incluam os homens como sujeitos igualmente responsáveis pela prevenção da infecção pelo ZIKV.

Uma limitação deste estudo foi o fato de a produção de dados ter ocorrido entre agosto e outubro, meses que apresentam baixas taxas de infestação pelo $A$. aegypti, o que pode ter influenciado a percep- 
ção de risco das gestantes. Seria importante também a realização de pesquisas incluindo a visão dos profissionais de saúde sobre as orientações fornecidas às gestantes pelos serviços de saúde sobre o ZIKV. A consolidação de conhecimentos nessa área poderá fornecer subsídios para o desenvolvimento de políticas públicas visando à capacitação dos profissionais de saúde e à adequada informação da população para o enfrentamento da doença.

\section{Colaboradores}

F. M. S. Lima desenvolveu o projeto de pesquisa que deu origem ao artigo, realizou a coleta, análise e interpretação dos dados, redigiu o artigo e aprovou a versão final para publicação. J. A. B. Iriart participou do desenvolvimento do projeto de pesquisa que deu origem ao artigo e da redação do artigo, fez a revisão crítica do conteúdo intelectual e aprovou a versão final para publicação.

\section{Informações adicionais}

ORCID: Fernanda Macedo da Silva Lima (00000001-9108-7831); Jorge Alberto Bernstein Iriart (0000-0002-9518-1240).

\section{Agradecimentos}

À Coordenação de Aperfeiçoamento de Pessoal de Nível Superior (CAPES) por possibilitar o desenvolvimento deste trabalho a partir da concessão da bolsa de pós-graduação.

\section{Referências}

1. Pitanguy J. Os direitos reprodutivos das mulheres e a epidemia do Zika vírus. Cad Saúde Pública 2016; 32:e00066016.

2. Ministério da Saúde. Orientações integradas de vigilância e atenção à saúde no âmbito da Emergência de Saúde Pública de Importância Nacional. Brasília: Ministério da Saúde; 2017.

3. Guedes GR, Coutinho RZ, Marteleto L, Pereira WHS, Duarte D. Signifying Zika: heterogeneity in the representations of the virus by history of infection. Cad Saúde Pública 2018; 34:e0003217.

4. Russell K, Oliver SE, Lewis L, Barfield WD, Cragan J, Meaney-Delman D, et al. Update: interim guidance for the evaluation and management of infants with possible congenital Zika virus infection - United States, August 2016. MMWR Morb Mortal Wkly Rep 2016; 65:870-8.

5. Franca GVA, Schuler-Faccini L, Oliveira WK, Henriques CMP, Carmo EH, Pedi VD, et al. Congenital Zika virus syndrome in Brazil: a case series of the first 1501 livebirths with complete investigation. Lancet 2016; 388:891-7.

6. França GVA, Pedi VD, Garcia MHO, Carmo GMI, Leal MB, Garcia LP. Síndrome congênita associada à infecção pelo vírus Zika em nascidos vivos no Brasil: descrição da distribuição dos casos notificados e confirmados em 2015-2016. Epidemiol Serv Saúde 2018; 27:e2017473.

7. Centro de Informações Estratégicas em Vigilância em Saúde, Diretoria de Vigilância da Saúde, Secretaria Municipal de Saúde de Salvador. Situação epidemiológica da microcefalia e outras alterações neurológicas em Salvador-Ba. Boletim Epidemiológico 2018; (12). http://www.cievs.saude.salvador.ba. gov.br/download/boletim-epidemiologicon-12_2018-situacao-epidemiologica-da-mi crocefalia-e-outras-alteracoes-neurologicas/\#.

8. World Health Organization. WHO statement on the first meeting of the International Health Regulations (2005) (IHR 2005) Emergency Committee on Zika virus and observed increase in neurological disorders and neonatal malformations. Geneva: World Health Organization; 2016. 
9. Netto EM, Moreira-Soto A, Pedroso C, Hoser C, Funk S, Kucharski AJ, et. al. High Zika virus seroprevalence in Salvador, Northeastern Brazil limits the potential for further outbreaks. mBio 2017; 8:e01390-17.

10. World Health Organization. Zika: the continuing threat. Bull World Health Organ 2019; 97:6-7.

11. Barbeito-Andrés J, Schuler-Faccini L, Garcez PP. Why is congenital Zika syndrome asymmetrically distributed among human populations? PLoS Biol 2018; 16:e2006592.

12. Lesser J, Kitron U. A geografia social do Zika no Brasil. Estud Av 2016; 30:167-75.

13. Secretaria de Vigilância em Saúde, Ministério da Saúde. Situação epidemiológica da infecção pelo vírus Zika no Brasil, de 2015 a 2017. Boletim Epidemiológico 2018; 49(47).

14. Meireles JFF, Neves CM, Morgado FFR, Ferreira MEC. Zika virus and pregnant women: a psychological approach. Psychol Health 2017; 32:798-809.

15. Linde AR, Siqueira CE. Women's lives in times of Zika: mosquito controlled lives? Cad Saúde Pública 2018; 34:e0178917.

16. Douglas M, Wildavsky A. Risk and culture: an essay on the selection of technical and environmental dangers. Berkeley: University of California Press; 1983.

17. Lupton D. Risk. London/New York: Routledge; 1999.

18. Bardin L. Análise de conteúdo. Lisboa: Edições 70; 2009.

19. Uchôa E, Vidal JM. Antropologia médica: elementos conceituais e metodológicos para uma abordagem da saúde e da doença. Cad Saúde Pública 1994; 10:497-504.

20. Souza CA, Mendes DCO, Mufato LF, Queiroz PS. Zika vírus: conhecimentos, percepções, e práticas de cuidados de gestantes infectadas. Rev Gaúcha Enferm 2018; 39:e20180025.

21. Borges ALV, Moreau C, Burke A, Santos AO, Chofakian CB. Women's reproductive health knowledge, attitudes and practices in relation to the Zika virus outbreak in northeast Brazil. PLoS One 2018; 13:e0195150.

22. Weldon CT, Riley-Powell AR, Aguerre IM, Nascimento RAC, Morrison AC, Oberhelman RA, et al. "Zika is everywhere": a qualitative exploration of knowledge, attitudes and practices towards Zika virus among women of reproductive age in Iquitos, Peru. PLoS Negl Trop Dis 2018; 12:e0006708.

23. Antunes MN, Alves W, Goveia FG, Oliveira AE, Cardoso JM. Arquivos visuais relacionados ao vírus Zika: imagens no Instagram como parte da constituição de uma memória da epidemia. RECIIS (Online) 2016; 10:1-13.
24. Carvalho LP. Vírus Zika e direitos reprodutivos: entre as políticas transnacionais, as nacionais e as ações locais. Cadernos de Gênero e Diversidade 2017; 3:134-57.

25. Diniz D. Vírus Zika e mulheres. Cad Saúde Pública 2016; 32:e00046316.

26. Marteleto LJ, Weitzman A, Coutinho RZ, Alves SV. Women's reproductive intentions and behaviors during the Zika epidemic in Brazil. Popul Dev Rev 2017; 43:199-227.

27. Spink MJP. Viver em áreas de risco: tensões entre gestão de desastres ambientais e os sentidos de risco no cotidiano. Ciênc Saúde Colet 2014; 19:3743-54.

28. Nawrotzki RJ, Guedes G, Carmo RL. Affluence and objective environmental conditions: evidence of differences in environmental concern in metropolitan Brazil. J Sustain Dev 2014; 7:173-93.

29. Marrs C, Olson G, Saade G, Hankins G, Wen T, Patel J, et al. Zika virus and pregnancy: a review of the literature and clinical considerations. Am J Perinatol 2016; 33:625-39.

30. Comissão Intergestores Bipartite. Resolução CIB no 117/2018. Diário Oficial do Estado da Bahia 2018; 7 mai.

31. Porto RM, Moura PRS. O corpo marcado: a construção do discurso midiático sobre Zika Vírus e microcefalia. Cadernos de Gênero e Diversidade 2017; 3:158-91.

32. World Health Organization. Prevention of sexual transmission of Zika virus. Geneva: World Health Organization; 2016.

33. Barbosa RM. Negociação sexual ou sexo negociado? Poder, gênero e sexualidade em tempos de Aids. In: Barbosa RM, Parker R, organizadores. Sexualidade pelo avesso. Rio de Janeiro: Instituto de Medicina Social, Universidade do Estado do Rio de Janeiro/São Paulo: Editora 34; 1999. p. 73-88.

34. Mane P, Aggleton P. Gênero e poder: comunicação, negociação e preservativo feminino. In: Barbosa RM, Parker R, organizadores. Sexualidade pelo avesso. Rio de Janeiro: Instituto de Medicina Social, Universidade do Estado do Rio de Janeiro/São Paulo: Editora 34; 1999. p. 215-28.

35. Castro MC, Han QC, Carvalho LR, Victora CG, França GVA. Implications of Zika virus and congenital Zika syndrome for the number of live births in Brazil. Proc Nat Acad Sci U S A 2018; 115:6177-82. 


\section{Abstract}

This study aimed to understand the meanings, risk perceptions, and strategies to prevent infection with the Zika virus developed by pregnant women with different socioeconomic conditions seen at public and private health services in the city of Salvador, Bahia State, Brazil, as well the contribution by their male partners in dealing with the risk of infection since the emergence of this virus in Brazil. A qualitative study was performed with 18 semi-structured interviews, nine each with pregnant women seen in the public and private health systems, respectively. The resulting data revealed insufficient knowledge in pregnant women concerning important aspects of Zika virus infection. The pregnant women's socioenvironmental situation was an important factor for risk perception and preventive strategies. Women interviewed in the public health system felt more vulnerable to the risk of infection than women interviewed in the private health system, with a major impact on their psychosocial well-being. According to the women, their partners placed huge demands on them to adopt preventive measures, but the male partners themselves failed to take the same precautions, e.g., ignoring the risk of sexual transmission of the Zika virus. In conclusion, three years since the outbreak reached Brazil, the Zika virus still has a major impact on the lives of pregnant women. It is crucial to strengthen health communications activities to guarantee the availability of information on the disease that responds adequately to the population's needs.

Zika Virus; Pregnancy; Microcephaly; Risk Management; Gender and Health

\section{Resumen}

Este estudio tuvo como objetivo comprender los significados, percepción de riesgo y estrategias de prevención frente a la infección por el virus Zika, desarrolladas por gestantes con diferentes condiciones socioeconómicas, atendidas en servicios de salud públicos y privados de la ciudad de Salvador, Bahía, Brasil, así como la contribución de sus parejas para lidiar con el riesgo de infección tras el surgimiento de este virus en Brasil. Se realizó un estudio cualitativo, a partir del desarrollo de 18 entrevistas semiestructuradas, siendo nueve con gestantes atendidas en el sector público de salud y nueve con gestantes atendidas en el sector privado de salud. Los datos producidos demostraron insuficiencias en el conocimiento de las gestantes sobre aspectos importantes de la infección por el virus Zika. La situación socioambiental en la que las gestantes están sometidas fue un factor importante para la percepción de riesgo y estrategias de prevención. Gestantes entrevistadas en el sector público de salud demostraron sentirse más vulnerables frente al riesgo de infección en el ambiente donde viven, que las gestantes entrevistadas en el sector privado de salud, con un gran impacto sobre su bienestar psicosocial. Según las gestantes, las parejas ejercieron una intensa presión para que adoptaran acciones preventivas sin que, sin embargo, tuvieran los mismos cuidados, desconsiderando el riesgo de transmisión del virus por vía sexual. Se concluye que, tras aproximadamente tres años de la epidemia en el país, el virus Zika todavía posee un gran impacto sobre la vida de las gestantes y es imprescindible fortalecer las acciones de comunicación en salud para asegurar la puesta a disposición de información que responda adecuadamente a las necesidades de la población sobre la enfermedad.

Virus Zika; Embarazo; Microcefalia; Gestión de Riesgos; Género y Salud
Recebido em 29/Jul/2019

Versão final reapresentada em 25/Fev/2020

Aprovado em 06/Jul/2020 